\title{
EFEITO DE ANTIOXIDANTES NO ENRAIZAMENTO DE MINIESTACAS DE CLONES DE Eucalyptus grandis X E. urophylla ${ }^{1}$
}

\author{
Patrícia Bueno Goulart², Aloisio Xavier ${ }^{3}$ e José Maria Moreira Dias ${ }^{4}$
}

\begin{abstract}
RESUMO - Este estudo teve como objetivo avaliar a eficiência dos antioxidantes ácido ascórbico, carvão ativado e polivinilpirrolidona (PVP) no enraizamento de miniestacas de quatro clones de Eucalyptus grandis $\mathrm{x}$ E. urophylla. As miniestacas foram coletadas em minijardim clonal desenvolvido em sistema de hidroponia em canaletas. Experimentalmente, foram testadas cinco concentrações de ácido ascórbico, quatro de carvão ativado e sete de PVP, nos quatro clones estudados. Foram realizadas avaliações quanto ao porcentual de enraizamento e crescimento das miniestacas enraizadas em casa de vegetação, casa de sombra e pleno sol. Concluiu-se que as respostas dos clones à aplicação dos antioxidantes ácido ascórbico, carvão ativado e PVP foram variadas e específicas, indicando efeito genotípico (clone) quanto às características avaliadas.
\end{abstract}

Palavras-chave: Miniestaquia, Estaquia, Propagação vegetativa e Silvicultura clonal

\section{EFFECT OF ANTIOXIDANTS ON THE ROOTING OF MINI-CUTTINGS OF Eucalyptus grandis $X$ E. urophylla CLONES}

\begin{abstract}
The objective of the present work was to evaluate the efficiency of the antioxidants ascorbic acid, activated carbon and polyvinylpyrrolidone (PVP) on the rooting of mini-cuttings of four clones of Eucalyptus grandis $x$ E. urophylla. The mini-cuttings were collected in a mini-clonal hedge developed in a hydroponic system in small gutters. Experimentally, five concentrations of ascorbic acid, four concentrations of activated carbon and seven concentrations of PVP were tested, for the four clones studied. Evaluation of the rooting percentage and growth of the rooted mini-cuttings were made in a greenhouse, a shade house and in the open sun. The obtained results led to the conclusion that there's a strong correlation between the genotypic differences of the analyzed materials and the plants rooting and their survival success as a response to the use of antioxidants ascorbic acid, activated carbon and polyvinylpyrrolidone (PVP) on different clones.
\end{abstract}

Keywords: Mini-cuttings, Stem-Cutting rooting, Vegetative propagation and Clonal forestry.

\section{INTRODUÇÃO}

Nos últimos anos, tem-se verificado constante aumento do interesse pela silvicultura clonal de espécies florestais, visando, principalmente, à uniformização dos plantios, maior produtividade, qualidade tecnológica da madeira e adaptação dos clones à área a ser implantada, aliado a um custo competitivo. O conhecimento das melhores técnicas de propagação vegetativa, aliadas às substâncias que promovam aumento no enraizamento, contribuem para melhorar a utilização de espécies com ganhos de produtividade (XAVIER et al., 2009).

A formação de raízes em estacas é um processo complexo, tanto do ponto de vista anatômico quanto fisiológico. A presença de carboidratos, proteínas, aminoácidos, vitaminas, compostos fenólicos e outras substâncias ainda não identificadas, além das auxinas,

\footnotetext{
${ }^{1}$ Recebido em 06.08.2007 e aceito para publicação em 25.08.2010.

${ }^{2}$ Programa de Pós-Graduação em Ciencia Florestal pela Universidade Federal de Viçosa, UFV, Brasil. E-mail: <pbgoulart@uol.com.br>. ${ }^{3}$ Universidade Federal de Viçosa, UFV, Brasil. E-mail: <xavier@ufv.br>.

${ }^{4}$ Universidade Federal de Viçosa,UFV, Brasil.
} 
contribuem para a iniciação de raízes adventícias quando combinados em concentrações e proporções adequadas (ONO e RODRIGUES, 1996).

Segundo HARTMANN et al. (2002), as plantas superiores, em condições adequadas, produzem várias substâncias, denominadas metabólitos secundários, as quais, em sua maioria, são de natureza fenólica. Segundo esses autores, a liberação de compostos fenólicos ocorre devido ao dano causado nas células durante a excisão dos propágulos vegetativos. Apesar de a oxidação de compostos fenólicos ser prejudicial às miniestacas, essas substâncias são essenciais às plantas, visto a importante função de regular a oxidação do AIA (ácido indolacético), principal auxina encontrada naturalmente nas plantas.

Vários estudos foram realizados com a finalidade de encontrar possíveis relações entre o potencial rizogênico dos propágulos e os compostos fenólicos. No início, ressaltava-se o efeito inibitório dos fenóis sobre a formação de raízes (KEFELI e KADYRON, 1971). Com o avanço das pesquisas, HAISSIG (1974) sugeriu que a formação de primórdios radiculares necessitava de conjugados AIA-fenóis, sintetizados com a participação de enzimas como polifenol oxidases e peroxidases. Ainda DEBERGH e READ (1991) descobriram que um grupo especial de compostos fenólicos são protetores das auxinas, por atuarem como antioxidantes, inibindo a oxidação do AIA.

Outras pesquisas têm indicado que, em geral, monofenóis e m-difenóis estimulam a oxidação do AIA, enquanto o-difenóis, p-difenóis e polifenóis inibem essa reação (LEE et al., 1982), bem como a não-relação do conteúdo de fenóis totais sobre o número de raízes, como em plantas de Castanea sativa (apresentou bom enraizamento) e Salix viminalis (apresentou baixo enraizamento), encontrado por GESTO et al. (1977), estimulando também a correlação positiva entre o enraizamento e o conteúdo de fenóis orto-dihidróxi e totais em espécies do gênero Prumus (RANA e CHADHA, 1989). Assim, WILSON e VAN STADEN (1990) constataram que a capacidade de alguns compostos fenólicos de estimular a formação de raízes adventícias se deve a uma possível ação protetora que exercem sobre o AIA, em consequência da inibição da AIAoxidase, e a reações de oxidação em geral, mantendo a célula em estado reduzido e permitindo a divisão celular. O tipo e quantidade desses cofatores determinam, parcialmente, se as estacas possuem maior ou menor facilidade para induzir os primórdios radiculares.
Alguns procedimentos para a redução da oxidação fenólica podem ser adotados, como: a utilização de substâncias antioxidantes, redução dos danos mecânicos e químicos causados, lavagem dos propágulos vegetativos em água corrente, utilização de meios básicos mais diluídos e remoção de sustâncias fenólicas, entre outros (XAVIER et al., 2009).

Quanto ao efeito do antioxidante, este consiste na inativação dos radicais livres, na complexação de íons metabólicos ou na redução dos peróxidos para produtos incapazes de formar radicais livres com potencial para se oxidar (ARAÚJO, 1985). Dentre as substâncias com efeito antioxidante, podem-se citar ácido ascórbico, ácido cítrico, polivinilpirrolidona (PVP), carvão ativado, L-cisteína, ditiotreitol, tiuréia, água de coco e albumina de soro bovino. Essas substâncias podem atuar inibindo a síntese ou a ação de enzimas ligadas à oxidação dos polifenóis ou agir como adsorventes dessas substâncias.

O carvão ativado e o PVP são considerados compostos adsorventes. O primeiro apresenta cargas residuais, as quais são capazes de adsorver substâncias fenólicas ou seus produtos da oxidação, como as quinonas; o PVP é uma poliamida utilizada em cromatografia de separação de ácidos aromáticos, aldeídos e fenóis pela sua função adsorvente (TEIXEIRA, 2004). Segundo esse mesmo autor, os fenóis são adsorvidos pelo PVP, por meio de ligações de hidrogênio, o que previne a oxidação e polimerização, além de adsorver os produtos da oxidação fenólica, ou seja, as quinonas.

O carvão ativado age promovendo a adsorção dos exsudatos liberados pelo explante, os quais provocam a oxidação. Também possui as propriedades de adsorver e reduzir a disponibilidade de auxina exógena no meio de cultura, induzindo a rizogênese (TAIZ e ZEIGER, 2004). O PVP reage com os compostos oxidantes e, de acordo com CORDEIRO et al. (2002), seu efeito principal no meio de cultura está relacionado com a capacidade de inibir a liberação de compostos fenólicos. Os ácidos cítrico e ascórbico reagem com os metais presentes no meio de cultura, evitando que estes fiquem disponíveis para se oxidarem (ARAÚJO, 1985; TAIZ e ZEIGER, 2004). De acordo com ZIV e HALEVY (1983), o ácido ascórbico e o ácido cítrico, em solução aquosa, reduzem a oxidação em explantes de Strelitzia spp.

Este estudo objetivou avaliar o efeito dos antioxidantes PVP, ácido ascórbico e carvão ativado quanto ao porcentual de enraizamento e crescimento 
das miniestacas enraizadas em casa de vegetação, casa de sombra e a pleno sol de quatro clones de Eucalyptus grandis x E. urophylla.

\section{MATERIAL E MÉTODOS}

\subsection{Material experimental}

Foram utilizados quatro clones de Eucalyptus grandis x E. urophylla provenientes da empresa International Paper do Brasil, localizada no Município de Mogi-Guaçu, São Paulo. O clima dessa região é do tipo Cwa (tropical, úmido e mesotérmico), segundo a classificação de Köeppen, com latitude de $22^{\circ} 21^{\prime}$ S, longitude de $48^{\circ} 58^{\prime} \mathrm{W}$ e altitude média de $639 \mathrm{~m}$. Apresenta precipitação média anual de $1.317 \mathrm{~mm}$ e temperatura média anual de $21^{\circ} \mathrm{C}$, com máxima média de $24{ }^{\circ} \mathrm{C}$ e mínima média de $16{ }^{\circ} \mathrm{C}$.

Para a seleção desses clones, foram considerados os porcentuais de área plantada e de enraizamento desses materiais genéticos, dados esses fornecidos pelo Departamento de Pesquisa daquela empresa.

A partir de plantas obtidas pela técnica de miniestaquia, o minijardim clonal foi instalado no Viveiro Experimental da International Paper do Brasil, localizado em uma estrutura de casa de vegetação coberta por plástico transparente, constituído pelos quatro clones em estudo (H1, H2, H3 e H4).

\subsection{Manejo do minijardim clonal}

Conforme a técnica de miniestaquia (XAVIER e WENDLING, 1998; HIGASHI et al., 2000, ASSIS et al., 2004 e XAVIER et al., 2009) e de acordo com os procedimentos de manejo adotados pela empresa, o minijardim clonal foi constituído de minicepas, obtidas pelo enraizamento de miniestacas oriundas de brotações de plantas propagadas pelo método da microestaquia. As miniestacas enraizadas, ao atingirem 10 a $12 \mathrm{~cm}$ de tamanho, tiveram seus ápices podados na altura de $8 \mathrm{~cm}$, constituindo, assim, as minicepas que forneceram as miniestacas (brotações) para a realização do experimento.

O sistema de manejo do minijardim clonal adotado foi o utilizado comercialmente pela empresa e composto por canaletas de alumínio revestidas com fibra de vidro, sobre as quais permaneceram as minicepas, plantadas em tubetes dispostos em bandejas de isopor cobertas por plástico dupla fase. A irrigação e a nutrição mineral foram efetuadas através do sistema automatizado de fertirrigação por inundação, de maneira que somente o sistema radicular permanecia em contato com a solução nutritiva. A cada $1 \mathrm{~h}$ o sistema era acionado, irrigando por 20 min e atingindo cerca de $6 \mathrm{~cm}$ de altura do tubete. Após esse período, a canaleta era esvaziada, e a solução nutritiva retornava à caixa de armazenagem da solução, sendo esta trocada a cada sete dias, e, diariamente, eram mensurados a Ec (condutividade elétrica, usada para medir a quantidade de sais presentes em solução) e o pH da solução. Nesse período, a Ec variou de 2,00 a 2,40 mS cm-1 e o pH, de 3,05 a 5,76. Em 500 L de solução nutritiva, adicionaram-se $20 \mathrm{~g}$ de nitrato de amônio, 200 g de nitrato de cálcio, 108 g de sulfato de amônio, $60 \mathrm{~g}$ de micronutrientes obtidos pelo produto Quelatec $\mathrm{AZ}^{\circledR}$ e 740 g de Phytus Super $\mathrm{K}^{\circledR}$. O Quelatec $\mathrm{AZ}{ }^{\circledR}$ constitui-se de quelato solúvel de micronutrientes, composto por ferro, manganês, zinco e cobre na forma quelatada e por boro e molibdênio na forma mineral. Já o Phytus Super $\mathrm{K}^{\circledR}$ foi constituído de um fertilizante composto por NPK (00:40:20).

\subsection{Obtenção, preparo, plantio e enraizamento das miniestacas}

As miniestacas foram coletadas no minijardim clonal e acondicionadas em caixas de PVC transparente, mantidas fechadas. Para manter as condições de turgescência do material vegetativo, pulverizou-se água, utilizando uma bomba costal, em intervalos de $10 \mathrm{~min}$, até a etapa de enraizamento, quando, então, as miniestacas foram preparadas com dimensões variando de 5 a $7 \mathrm{~cm}$ de comprimento e com um par de folhas, tendo a área foliar sido reduzida à metade de sua dimensão original.

Após o preparo das miniestacas, estas foram tratadas com os antioxidantes ácido ascórbico, carvão ativado e PVP associados com $500 \mathrm{mg} \mathrm{L}^{-1}$ de AIB para, posteriormente, serem plantadas e colocadas para enraizamento na casa de vegetação. Foram utilizadas as seguintes concentrações dos antioxidantes ácido ascórbico $\left(0,5,10,20\right.$ e $\left.40 \mathrm{mg} \mathrm{L}^{-1}\right)$, carvão ativado (0, 500, 1.000 e $\left.2.000 \mathrm{mg} \mathrm{L}^{-1}\right)$ e PVP $(0,500,1.000$, 2.000, 4.000, 8.000 e $\quad 16.000 \mathrm{mg} \mathrm{L}^{-1}$ ), via líquido, dissolvidos em solução de AIB a $500 \mathrm{mg} \mathrm{L}^{-1}$ (ácido indolbutírico - Merck S.A. - dissolvido em KOH a $1 \mathrm{~mol} \mathrm{~L}^{-1}$, diluído em água destilada autoclavada). As miniestacas tiveram suas bases $(2 \mathrm{~cm})$ mergulhadas na solução de antioxidante + AIB por 15 seg, antes de serem plantadas no substrato.

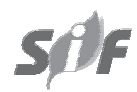

Revista Árvore, Viçosa-MG, v.34, n.6, p.961-972, 2010 
Operíodo compreendido entre o preparo das miniestacas, seus tratamentos com os cofatores e plantio no substrato, na casa de vegetação, foi sempre inferior a $30 \mathrm{~min}$.

No enraizamento das miniestacas, utilizaram-se como recipientes tubetes plásticos de $55 \mathrm{~cm}^{3}$ de capacidade, contendo substrato constituído de partes iguais de vermiculita de granulometria fina e casca de arroz carbonizada. A nutrição mineral utilizada no substrato foi composta por 4,00 kg m³ de Fosmag 500B (MANAH, São Paulo), composto por $4 \%$ de N, $14 \%$ de P, $7 \%$ de K, $14 \%$ de Ca, $9 \%$ de S, $2 \%$ de $\mathrm{Mg}$ e $0,5 \%$ de B; $5,40 \mathrm{~kg} \mathrm{~m}^{-3}$ de NPK (32:00:03) e 3,06 $\mathrm{kg} \mathrm{m}^{-3}$ de cloreto de potássio.

O processo de enraizamento das miniestacas foi conduzido em casa de vegetação climatizada (umidade relativa do ar de $80 \%$ e temperatura em torno de $27^{\circ} \mathrm{C}$ ), com permanência de 25 dias. Posteriormente, as miniestacas foram transferidas para casa de sombra (permanência de 10 dias para aclimatização) e, finalmente, a pleno sol até completarem 50 dias de idade.

Foram instalados experimentos independentes dos diferentes tipos de antioxidantes testados, os quais seguiram o delineamento experimental inteiramente casualizado, em arranjo fatorial 5 x 4 para ácido ascórbico (constituído de cinco doses), fatorial 4 x 4 para carvão (constituído de quatro doses) e fatorial 7 x 4 para PVP (constituído de sete doses), considerando-se os quatro clones em estudo (H1, H2, H3 e H4), em quatro repetições e parcelas compostas de 16 miniestacas/repetição.

\subsection{AVALIAÇÕES EXPERIMENTAIS}

As avaliações das plantas foram realizadas quanto ao porcentual de sobrevivência das miniestacas na saída da casa de vegetação (aos 25 dias de idade), porcentual de enraizamento e altura das miniestacas na saída da casa de sombra (aos 35 dias de idade). Aos 50 dias de idade a pleno sol, avaliaram-se o porcentual de sobrevivência, a altura, o diâmetro de colo e a massa da matéria seca da parte aérea e da raiz das miniestacas enraizadas.

As avaliações de altura, diâmetro de colo, massa da matéria seca da parte aérea e do sistema radicular foram realizadas em quatro miniestacas/repetição selecionadas ao acaso em cada tratamento.

Os dados resultantes foram submetidos às análises de variância e regressão, utilizando-se os programas Statistica e Excel.

\section{RESULTADOS E DISCUSSÃO}

\subsection{Eficiência do ácido ascórbico no enraizamento adventício}

Com base nos resultados da análise de variância das características avaliadas (Tabela 1), observou-se efeito significativo, pelo teste $\mathrm{F}(\mathrm{P}<0,05)$, da interação "clone $\mathrm{x}$ tratamento" sobre todas as características avaliadas, indicando respostas diferenciadas dos clones em relação ao antioxidante e aos tratamentos adotados.

Tabela 1 - Resultados da análise de variância das características de sobrevivência das miniestacas na saída da casa de vegetação (SOBCV), do porcentual de enraizamento (ENRCS) e da altura (ALTCS) das miniestacas na saída da casa de sombra; e de sobrevivência (SOB50), altura (ALT50), diâmetro de colo (DC50) e da massa de matéria seca da parte aérea (PSPA) e do sistema radicular (PSR) das plantas aos 50 dias de idade, em função das concentrações do antioxidante ácido ascórbico associado a $500 \mathrm{mg} \mathrm{L}^{-1}$ de AIB, dos quatro clones de Eucalyptus grandis x E. urophylla.

Table 1 - Results of the Analysis of Variance (ANOVA) of survival data on mini-cuttings of four Eucalyptus grandis $x$ E. urophylla clones regarding greenhouse exit survival (SOBCV), shade house exit mini-cuttings rooting percentage (ENRCS) and height (ALTCS); survival (SOB50), height (ALT50), root collar diameter (DC50) and dry mass of the aerial portion (PSPA) and root system (PSR) of the plants at 50 days of age, as a result of concentrations of the ascorbic acid antioxidant associated with $500 \mathrm{mg} \mathrm{L}^{-1} \mathrm{IBA}$.

\begin{tabular}{|c|c|c|c|c|c|c|c|c|c|}
\hline \multirow{2}{*}{$\begin{array}{l}\text { Fontes de } \\
\text { variação }\end{array}$} & \multirow[t]{2}{*}{ GL } & \multicolumn{8}{|c|}{ Quadrados médios } \\
\hline & & $\begin{array}{c}\text { SOBCV } \\
(\%)\end{array}$ & $\begin{array}{c}\text { ENRCS } \\
(\%)\end{array}$ & $\begin{array}{l}\text { ALTCS } \\
(\mathrm{cm})\end{array}$ & $\begin{array}{l}\text { SOB50 } \\
(\%)\end{array}$ & $\begin{array}{l}\text { ALT50 } \\
(\mathrm{cm})\end{array}$ & $\begin{array}{l}\text { DC50 } \\
(\mathrm{mm})\end{array}$ & $\begin{array}{c}\text { PSPA } \\
\text { (g) }\end{array}$ & $\begin{array}{l}\text { PSR } \\
\text { (g) }\end{array}$ \\
\hline$\overline{\text { Clone (C) }}$ & 3 & $2532,55^{*}$ & $10103,35^{*}$ & $3840,01^{*}$ & $11901,71^{*}$ & $4494,01^{*}$ & $15,67^{*}$ & $145,40^{*}$ & $19,65^{*}$ \\
\hline Trat. (T) & 4 & $506,10^{*}$ & $2799,07^{*}$ & $126,02^{*}$ & $2235,62^{*}$ & $129,50^{*}$ & $0,60^{\mathrm{ns}}$ & $1,68^{\mathrm{ns}}$ & $1,14^{\mathrm{ns}}$ \\
\hline $\mathrm{C}^{*} \mathrm{~T}$ & 12 & $600,18^{*}$ & $1527,91^{*}$ & $98,70^{*}$ & $1263,31^{*}$ & $103,94^{*}$ & $0,89^{*}$ & $13,68^{*}$ & $1,55^{*}$ \\
\hline Resíduo & 60 & 111,00 & 98,47 & 49,63 & 111,00 & 50,44 & 0,44 & 4,56 & 0,57 \\
\hline Média Geral & - & 91,3 & 70,7 & 31,3 & 66,1 & 34,5 & 2,9 & 6,4 & 1,9 \\
\hline $\mathrm{CV}_{\exp }(\%)$ & - & 18,9 & 19,8 & 25,7 & 23,9 & 24,1 & 26,0 & 22,1 & 22,7 \\
\hline
\end{tabular}

“ns” e “*” = não significativo e significativo, respectivamente, a 5\% de probabilidade, pelo teste F.

“ns" and “*” = not meaningful and significant, respectively, at $5 \%$ probability by $F$ test.

Revista Árvore, Viçosa-MG, v.34, n.6, p.961-972, 2010 
Os coeficientes de variação experimental encontrados variaram de 18,9até26,0\%, evidenciando-se razoável precisão experimental em relação às características estudadas, de acordo com os valores encontrados na literatura (RIBAS, 1997; WENDLING et al., 2000, WENDLING e XAVIER, 2005, TITON et al., 2006).

Nos clones H1 e H4, a aplicação de ácido ascórbico não influenciou significativamente a sobrevivência das miniestacas na saída da casa de vegetação, sendo observada no clone $\mathrm{H} 4$ tendência de decréscimo dos porcentuais a partir da dose de $20 \mathrm{mg} \mathrm{L}-1$ de ácido ascórbico (Figura 1). No clone H2, a não aplicação de ácido ascórbico apresentou os melhores resultados, e no clone $\mathrm{H} 3$ os resultados mais significativos de sobrevivência das miniestacas na saída da casa de vegetação foram obtidos com a aplicação de $40 \mathrm{mg}$ L-1 de ácido ascórbico.

Ao analisar o enraizamento adventício na saída da casa de sombra (Figura 1), observou-se que os clones H1, H2 e H3 apresentaram resultados semelhantes aos encontrados na saída da casa de vegetação. No entanto, no clone H4 a não aplicação de ácido ascórbico resultou nos melhores resultados de enraizamento adventício na saída da casa de sombra.

Quanto à altura das miniestacas na saída da casa de sombra (Figura 2), observou-se que no clone H1 os melhores resultados de crescimento das miniestacas foram obtidos com doses entre 20 e 40 mg L-1 de ácido

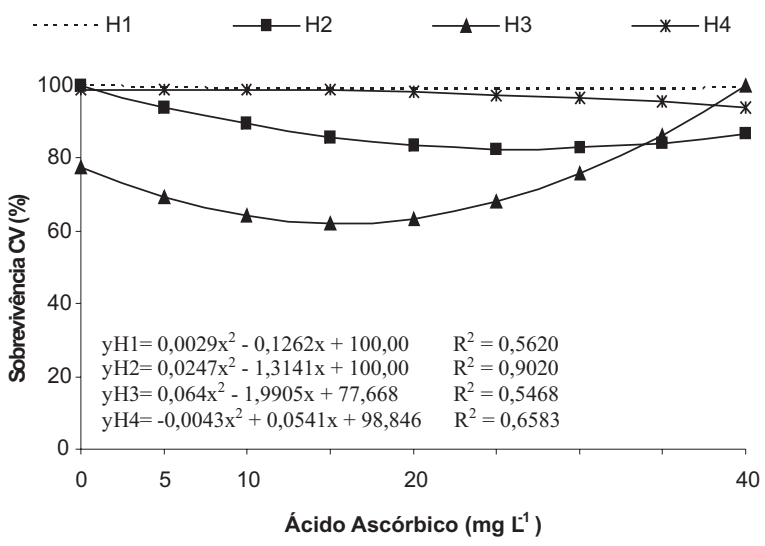

ascórbico. Nos clones H2 e H4, com a não aplicação de ácido ascórbico ocorreram os melhores resultados de crescimento em altura das miniestacas. Já no clone H3 se observou tendência dos melhores resultados de crescimento em altura das miniestacas na saída da casa de sombra a partir de 40 mg L-1 de ácido ascórbico.

No clone H1, os melhores resultados de altura das miniestacas a pleno sol (Figura 2) foram observados a partir da aplicação de 10 mg L-1 de ácido ascórbico. Já os clones H2, H3 e H4 apresentaram resultados de crescimento em altura das miniestacas a pleno sol semelhantes aos encontrados na saída da casa de sombra.

Quanto à sobrevivência das plantas a pleno sol, aos 50 dias (Figura 3) observou-se que nos clones H1, H2 e H4 os melhores resultados foram obtidos com a não aplicação de ácido ascórbico. No entanto, no clone H3 os melhores resultados de sobrevivência das plantas a pleno sol foram obtidos com a aplicação de doses a partir de $40 \mathrm{mg} \mathrm{L}^{-1}$ de ácido ascórbico. Segundo WENDLING et al. (2002), a sobrevivência das plantas aos 50 dias de idade é uma avaliação que já mostra efeitos mais drásticos do ambiente, sendo mais fácil a ocorrência de diferenças entre os tratamentos e clones.

A hipótese era de que a aplicação, nas miniestacas, de ácido ascórbico, associado ao AIB, promovesse aumento nos índices de enraizamento e sobrevivência, o que foi confirmado apenas no clone H3. Nos três outros clones, a utilização desse antioxidante não foi favorável.

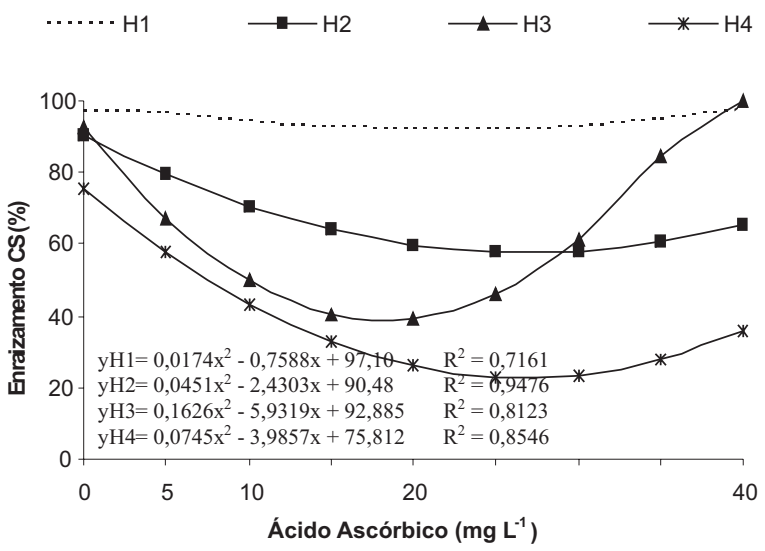

Figura 1 - Sobrevivência e enraizamento das miniestacas na saída da casa de vegetação e na saída da casa de sombra, aos 25 e 35 dias de idade, respectivamente, em função da aplicação do antioxidante ácido ascórbico associado a 500 $\mathrm{mg} \mathrm{L}^{-1}$ de AIB, dos quatro clones de Eucalyptus grandis x E. urophylla.

Figure 1 - Survival and rooting of mini-cuttings of four Eucalyptus grandis $x$ E. urophylla clones greenhouse exit and shade house exit, at 25 and 35 days of age, respectively, as a result of the application of the ascorbic acid antioxidant associated with $500 \mathrm{mg} \mathrm{L}^{-1}$ IBA. 

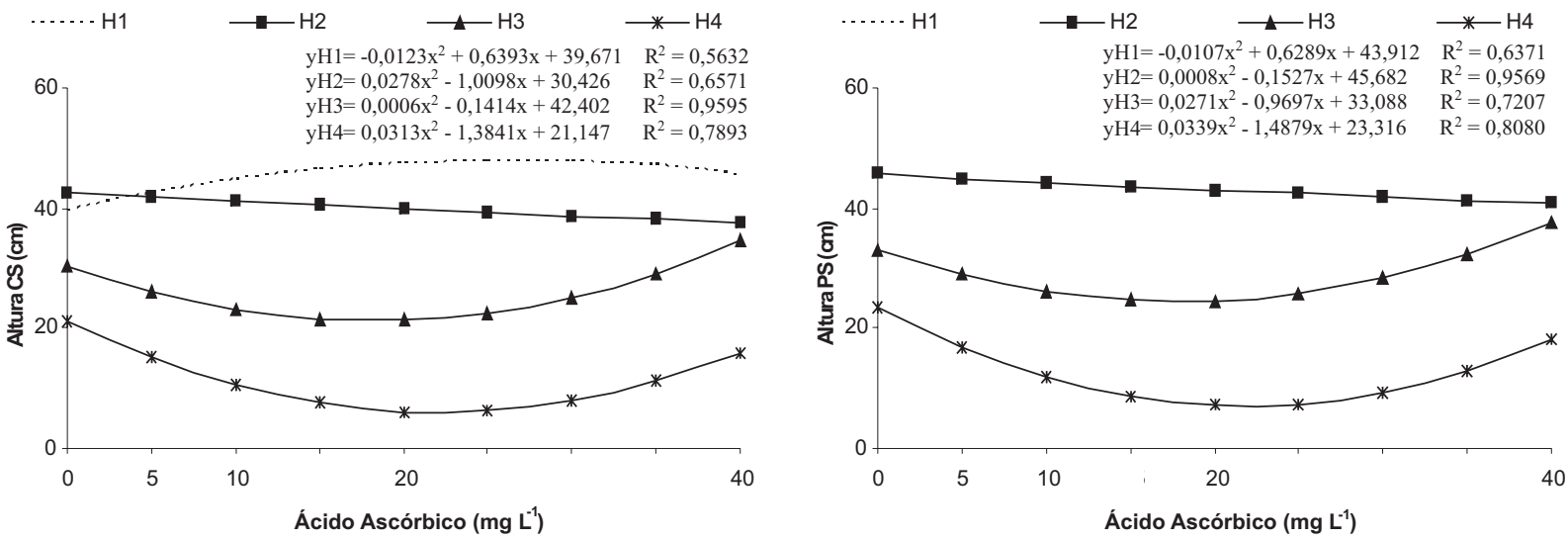

Figura 2 - Altura das miniestacas na saída da casa de sombra e a pleno sol, aos 35 e 50 dias de idade, respectivamente, em função da aplicação do antioxidante ácido ascórbico associado a $500 \mathrm{mg} \mathrm{L}^{-1}$ de AIB, dos quatro clones de Eucalyptus grandis x E. urophylla.

Figure 2 - Mini-cuttings of four Eucalyptus grandis $x$ E. urophylla clones shade house exit and in full sun height, at 35 and 50 days of age, respectively, as a result of the application of the ascorbic acid antioxidant associated with $500 \mathrm{mg} \mathrm{L}^{-1} \mathrm{IBA}$.

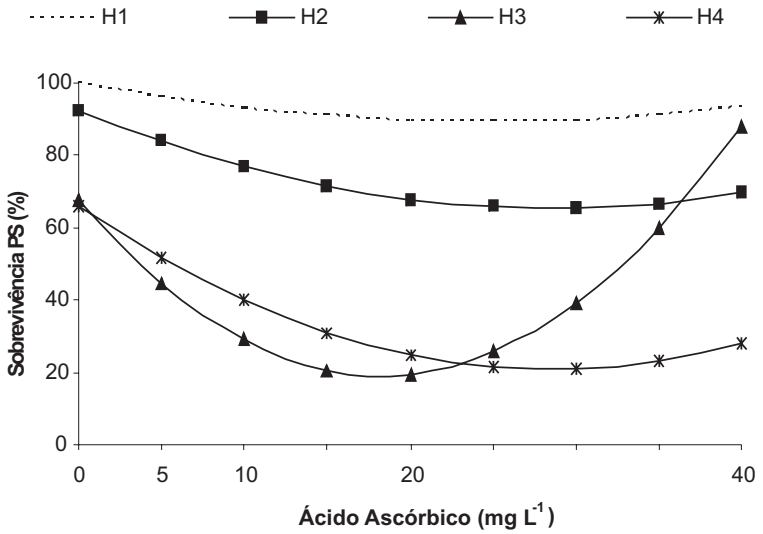

Figura 3 - Sobrevivência das miniestacas a pleno sol, aos 50 dias de idade, em função da aplicação do antioxidante ácido ascórbico associado a $500 \mathrm{mg}$ $\mathrm{L}^{-1}$ de AIB, dos quatro clones de Eucalyptus grandis $\mathrm{x}$ E. urophylla.

Figure 3-Mini-cuttings of four Eucalyptus grandis $x$ E. urophylla clones survival in full sun, at 50 days of age, as a result of the application of the ascorbic acid antioxidant associated with $500 \mathrm{mg} \mathrm{L}^{-1} \mathrm{IBA}$.

Hoffmann et al. (1995), trabalhando com estacas de mirtilo (frutífera de clima temperado), não verificaram efeito do ácido ascórbico associado ao AIB no enraizamento. Não foram encontrados na literatura trabalhos que utilizaram ácido ascórbico no tratamento de estacas de Eucalyptus spp.
O ácido ascórbico, de forma geral, mostrou-se benéfico como cofator do AIB em apenas um clone a partir da dose de $40 \mathrm{mg} \mathrm{L}^{-1}$. Nos demais clones, a utilização desse antioxidante não melhorou os índices de enraizamento e de sobrevivência das miniestacas.

\subsection{Eficiência do carvão ativado no enraizamento adventício}

Com base nos resultados da análise de variância das características avaliadas (Tabela 2), observou-se efeito significativo, pelo teste $\mathrm{F}(\mathrm{P}<0,05)$, da interação “clone x tratamento" sobre algumas das características avaliadas, indicando respostas diferenciadas dos clones em relação ao antioxidante e aos tratamentos adotados.

Os coeficientes de variação experimental variaram de 6,0 até 29,7\%, evidenciando-se razoável precisão experimental em relação às características estudadas, de acordo com os valores encontrados na literatura (RIBAS, 1997; WENDLING et al., 2000, WENDLING e XAVIER, 2005, TITON et al., 2006).

O comportamento dos clones H1, H2, H3 e H4 foram semelhante entre si quanto ao enraizamento das miniestacas na saída da casa de sombra (Figura 4), e a não aplicação de carvão ativado apresentou os melhores resultados.

Quanto à sobrevivência das miniestacas a pleno sol (Figura 4), observou-se que o comportamento dos clones H1, H2 e H3 foi semelhante ao verificado na saída da casa de sombra, e a não aplicação de carvão ativado apresentou os melhores resultados. Já no clone H4 a 
Tabela 2 - Resultados da análise de variância das características de sobrevivência das miniestacas na saída da casa de vegetação (SOBCV); do porcentual de enraizamento (ENRCS) e altura (ALTCS) das miniestacas na saída da casa de sombra; e de sobrevivência (SOB50), altura (ALT50), diâmetro de colo (DC50) e da massa de matéria seca da parte aérea (PSPA) e do sistema radicular (PSR) das plantas aos 50 dias de idade, em função das concentrações de carvão ativado associado a $500 \mathrm{mg} \mathrm{L}^{-1}$ de AIB, dos quatro clones de Eucalyptus grandis x E. urophylla.

Table 2 - Results of the Analysis of Variance (ANOVA) of survival data on mini-cuttings of four Eucalyptus grandis $x$ E. urophylla clones regarding greenhouse exit survival ( $S O B C V)$; shade house exit mini-cuttings rooting percentage (ENRCS) and height (ALTCS); survival (SOB50), height (ALT50), root collar diameter (DC50) and dry mass of the aerial portion (PSPA) and root system (PSR) of the plants at 50 days of age, as a result of the concentrations of activated carbon associated with $500 \mathrm{mg} \mathrm{L}^{-1} \mathrm{IBA}$.

\begin{tabular}{lccccccccc}
\hline $\begin{array}{l}\text { Fontes de } \\
\text { variação }\end{array}$ & GL & \multicolumn{9}{c}{ Quadrados médios } \\
\cline { 2 - 8 } & & $\begin{array}{c}\text { SOBCV } \\
(\%)\end{array}$ & $\begin{array}{c}\text { ENRCS } \\
(\%)\end{array}$ & $\begin{array}{c}\text { ALTCS } \\
(\mathrm{cm})\end{array}$ & $\begin{array}{c}\text { SOB50 } \\
(\%)\end{array}$ & $\begin{array}{c}\text { ALT50 } \\
(\mathrm{cm})\end{array}$ & $\begin{array}{c}\text { DC50 } \\
(\mathrm{mm})\end{array}$ & $\begin{array}{c}\text { PSPA } \\
(\mathrm{g})\end{array}$ & $\begin{array}{c}\text { PSR } \\
(\mathrm{g})\end{array}$ \\
\hline Clone (C) & 3 & $31,53^{\text {ns }}$ & $2318,32^{*}$ & $4156,96^{*}$ & $3698,53^{*}$ & $4965,93^{*}$ & $21,81^{*}$ & $195,05^{*}$ & $27,82^{*}$ \\
Trat. (T) & 3 & $34,79^{\text {ns }}$ & $1916,30^{*}$ & $93,75^{*}$ & $1782,84^{*}$ & $142,07^{*}$ & $1,92^{*}$ & $13,52^{\text {ns }}$ & $2,53^{\text {ns }}$ \\
C*T & 9 & $42,39^{\text {ns }}$ & $651,11^{*}$ & $79,72^{*}$ & $663,05^{*}$ & $68,10^{*}$ & $0,37^{\text {ns }}$ & $4,89^{\text {ns }}$ & $1,38^{\text {ns }}$ \\
Resíduo & 48 & 33,16 & 146,69 & 24,52 & 156,86 & 30,67 & 0,25 & 3,76 & 1,68 \\
Média Geral & - & 97,4 & 79,8 & 31,1 & 73,3 & 34,1 & 2,7 & 6,7 & 2,1 \\
CV $_{\text {exp }}$ (\%) & - & 6,0 & 25,3 & 29,0 & 29,7 & 28,7 & 22,7 & 24,8 & 20,3 \\
\hline
\end{tabular}

“ns” e “*” = não significativo e significativo, respectivamente, a 5\% de probabilidade, pelo teste F. “ns" and "*” = not meaningful and significant, respectively, at $5 \%$ probability by $F$ test.
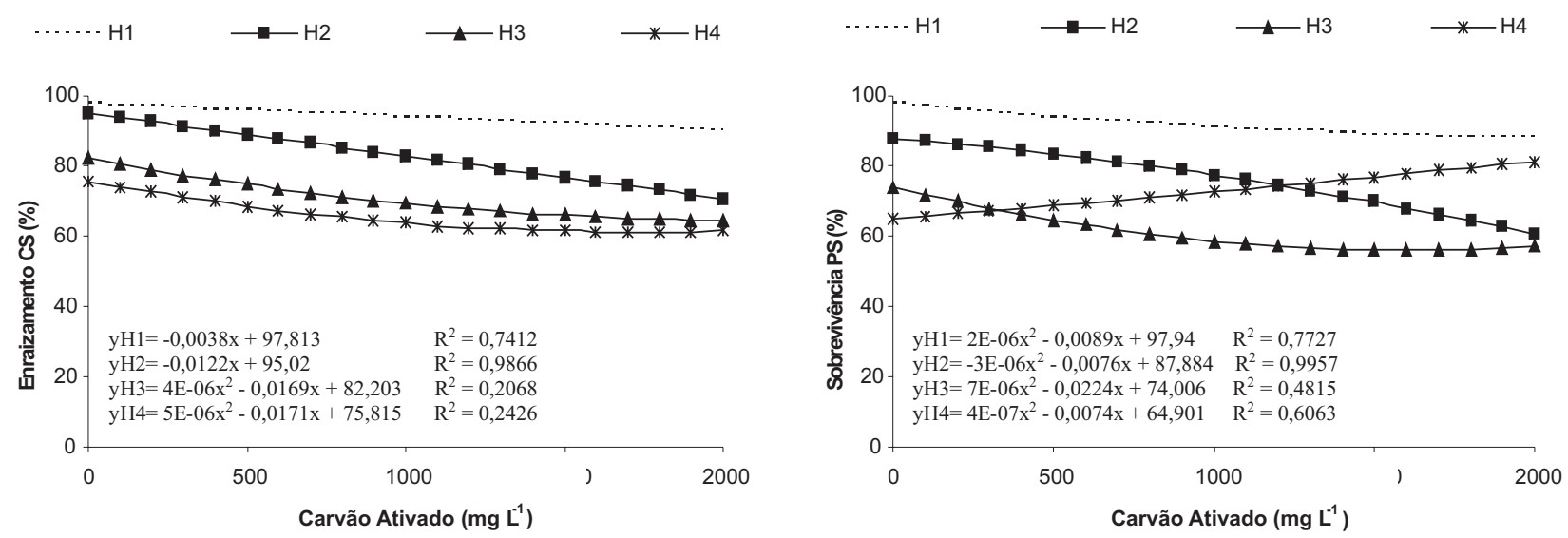

Figura 4 - Enraizamento e sobrevivência das miniestacas na saída da casa de vegetação e a pleno sol, aos 35 e 50 dias de idade, respectivamente, em função da aplicação do antioxidante carvão ativado associado a $500 \mathrm{mg} \mathrm{L}^{-1}$ de AIB, dos quatro clones de Eucalyptus grandis x E. urophylla.

Figure 4-Mini-cuttings of four Eucalyptus grandis $x$ E. urophylla clones in full sun and greenhouse exit rooting and survival, at 35 and 50 days of age, respectively, as a result of the application of activated carbon antioxidant associated with $500 \mathrm{mg} \mathrm{L}^{-1}$ IBA.

aplicação de doses crescentes de carvão ativado foi benéfica para o aumento nos índices de sobrevivência das miniestacas a pleno sol, em que se verificaram os melhores resultados a partir de $2.000 \mathrm{mg} \mathrm{L}^{-1}$ de carvão ativado.

Em relação à altura das miniestacas na saída da casa de sombra (Figura 5), notou-se que, nos clones H1 e H3, os melhores índices de crescimento em altura foram obtidos com a não aplicação de carvão ativado, e no clone H2 a aplicação de doses entre 1.000 e $2.000 \mathrm{mg} \mathrm{L}^{-1}$ de carvão ativado apresentou os melhores resultados. Já no clone H4 se observou tendência de acréscimo nos índices de crescimento em altura das miniestacas na saída da casa de sombra com o aumento das doses de carvão ativado, ressaltando-se que doses a partir de $2.000 \mathrm{mg} \mathrm{L}^{-1}$ de carvão ativado apresentaram os melhores resultados. Os resultados de altura das miniestacas a pleno sol (Figura 5) foram semelhantes aos observados na saída da casa de sombra. 


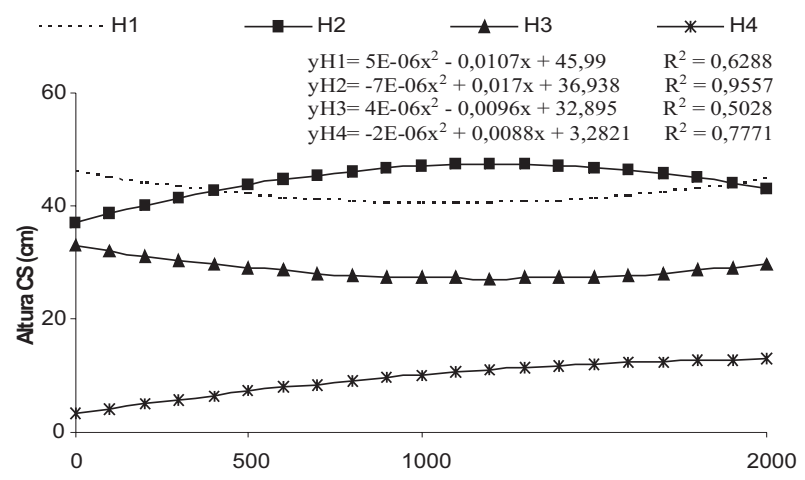

Carvão Ativado (mg L-1 ${ }^{-1}$

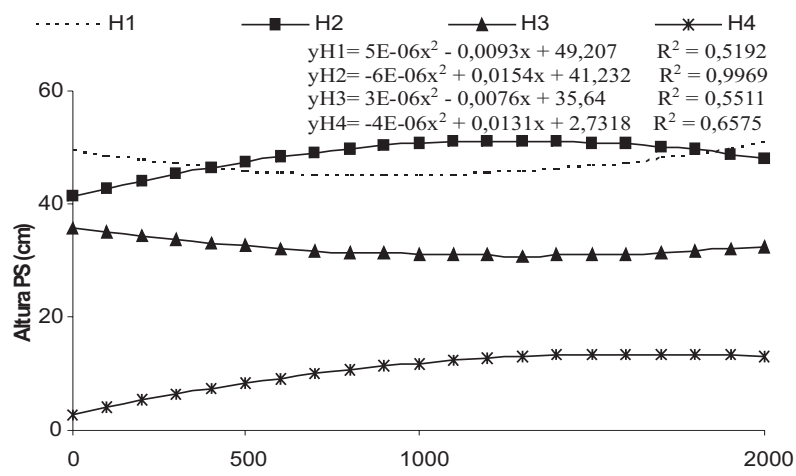

Carvão Ativado $\left(\mathrm{mg} \mathrm{L}^{-1}\right)$

Figura 5 - Altura das miniestacas na saída da casa de sombra e a pleno sol, aos 35 e 50 dias de idade, respectivamente, em função da aplicação do antioxidante carvão ativado associado a $500 \mathrm{mg} \mathrm{L}^{-1}$ de AIB, dos quatro clones de Eucalyptus grandis x E. urophylla.

Figure 5 - Mini-cuttings of four Eucalyptus grandis $x$ E. urophylla clones shade house exit and in full sun height, at 35 and 50 days of age, respectively, as a result of the application of activated carbon antioxidant associated with $500 \mathrm{mg} \mathrm{L}^{-1} \mathrm{IBA}$.

Quanto ao diâmetro de colo das miniestacas (Figura 6), observou-se que o clone $\mathrm{H} 1$ apresentou os maiores índices de crescimento de diâmetro de colo das miniestacas em relação aos clones estudados, sendo os melhores resultados, semelhantemente ao clone H2, obtidos a partir de $2.000 \mathrm{mg} \mathrm{L}^{-1}$ de carvão ativado. No clone H3, a aplicação de carvão ativado não exibiu resultados significativos dos índices de crescimento de diâmetro de colo das miniestacas. O clone $\mathrm{H} 4$ teve os melhores índices de crescimento de diâmetro de colo das miniestacas com a aplicação de doses entre 1.000 e $2.000 \mathrm{mg} \mathrm{L}^{-1}$ de carvão ativado.

Em relação às características de sobrevivência na saída da casa de vegetação e peso de matéria seca da parte aérea e da raiz das plantas a pleno sol, observaram-se, com base na Tabela 2 apenas diferenças entre os clones; no entanto, não foram verificadas diferenças significativas em relação aos tratamentos impostos, bem como da interação “clone x tratamento”, indicando, de certa forma, a baixa eficiência desse antioxidante no processo de produção de mudas a partir do enraizamento de miniestacas de clones de Eucalyptus grandis x E. urophylla.

A hipótese era de que a aplicação, nas miniestacas, de carvão ativado associado ao AIB promovesse aumento nos índices de enraizamento e sobrevivência, sendo confirmado apenas no clone H4. Nos três outros clones, a utilização desse antioxidante não melhorou os índices de enraizamento e sobrevivência.
Na literatura revisada não foram encontrados trabalhos que utilizassem carvão ativado no tratamento de estacas de Eucalyptus spp. O trabalho de BERARDI et al. (1993), com plântulas de Pyrus calleryana, indicou que o enraizamento in vitro foi promovido pelo AIB e ANA, e o carvão ativado associado ao AIB não apresentou efeito benéfico. Erig et al. (2004) também

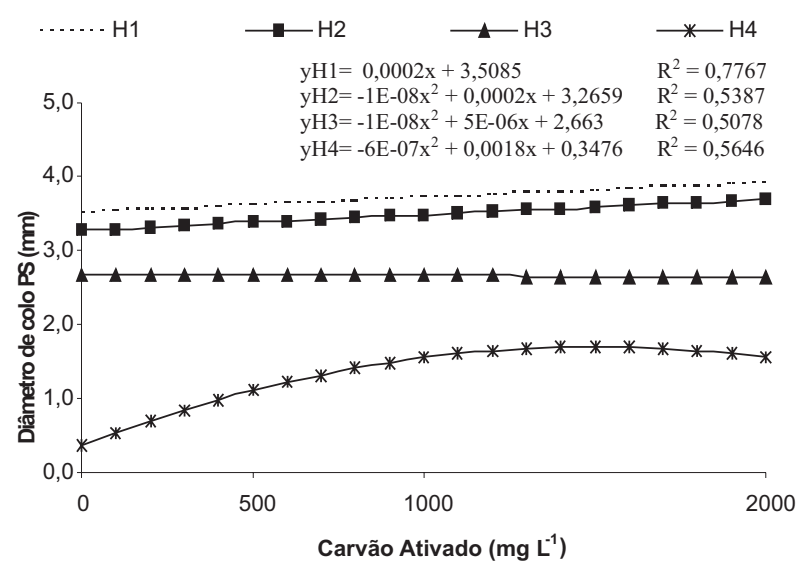

Figura 6 - Diâmetro de colo das miniestacas a pleno sol, aos 50 dias de idade, em função da aplicação do antioxidante carvão ativado associado a $500 \mathrm{mg}$ $\mathrm{L}^{-1}$ de AIB, dos quatro clones de Eucalyptus grandis $\mathrm{x}$ E. urophylla.

Figure 6-Mini-cuttings of four Eucalyptus grandis $x$ E. urophylla clones collar diameter in full sun, at 50 days of age, as a result of the application of activated carbon antioxidant associated with $500 \mathrm{mg} \mathrm{L}^{-1}$ IBA. 
verificaram que a utilização de carvão ativado no meio de cultura não favoreceu o enraizamento das microestacas de pereira (Pyrus communis L.) em razão, provavelmente, da retenção de auxinas, diminuindo, assim, o seu efeito. Já no louro-pardo (Cordia trichotoma) o meio de cultura suplementado com AIB e carvão ativado apresentou o melhor porcentual de enraizamento das brotações (MANTOVANI et al., 2001).

O carvão ativado, de forma geral, mostrou-se benéfico como cofator do AIB em apenas um clone a partir de $2.000 \mathrm{mg} \mathrm{L}^{-1}$ de carvão ativado.

\subsection{Eficiência do PVP no enraizamento adventício}

Com base nos resultados da análise de variância das características avaliadas (Tabela 3), observou-se efeito significativo, pelo teste $\mathrm{F}(\mathrm{P}<0,05)$, da interação “clone x tratamento" das características avaliadas, exceto quanto à característica massa da matéria seca do sistema radicular (PSR), indicando respostas diferenciadas dos clones em relação ao antioxidante e aos tratamentos adotados.

Os coeficientes de variação experimental encontrados variaram de 11,1 até 29,5\%, evidenciando-se razoável precisão experimental em relação às características estudadas, de acordo com os valores encontrados na literatura (RIBAS, 1997; WENDLING et al., 2000, WENDLING e XAVIER, 2005, TITON et al., 2006).
Analisando os resultados de enraizamento na saída da casa de sombra (Figura 7), observou-se que no clone H1 a utilização de PVP não influenciou o enraizamento das miniestacas. Os melhores resultados de enraizamento no clone $\mathrm{H} 2$ foram com a aplicação de doses superiores a $8.000 \mathrm{mg} \mathrm{L}^{-1}$ de PVP, no clone H3 com a aplicação de até $4.000 \mathrm{mg} \mathrm{L}^{-1}$ de PVP e no clone $\mathrm{H} 4$ com a aplicação de doses entre 4.000 e $8.000 \mathrm{mg} \mathrm{L}^{-1}$ de PVP. Entretanto, para essa característica especificamente vale salientar que em todos os clones os coeficientes de determinação $\left(\mathrm{R}^{2}\right)$ nas análises de regressão apresentaram valores considerados baixos, denotando maior atenção na interpretação das equações de regressão, visando explicar as respostas de enraizamento das miniestacas na saída da casa de sombra.

Quanto à sobrevivência das miniestacas a pleno sol (Figura 7), observou-se que nos clones H1 e H2 os melhores resultados foram obtidos a partir da aplicação de $8.000 \mathrm{mg} \mathrm{L}^{-1}$ de PVP. No clone H3, os melhores índices de sobrevivência das miniestacas a pleno sol foram obtidos aplicando-se até $4.000 \mathrm{mg} \mathrm{L}^{-1}$ de PVP e no o clone $\mathrm{H} 4$, entre 4.000 e $8.000 \mathrm{mg} \mathrm{L}^{-1}$ de PVP.

Na Figura 8, observa-se no clone H1 tendência de que doses a partir de $16.000 \mathrm{mg} \mathrm{L}^{-1}$ de PVP apresentaram os melhores índices de crescimento em altura das miniestacas a pleno sol. Nos clones $\mathrm{H} 2$, H3 e H4, a aplicação de doses entre 4.000 e $8.000 \mathrm{mg} \mathrm{L}^{-1}$ de PVP

Tabela 3 - Resultados da análise de variância das características de sobrevivência das miniestacas na saída da casa de vegetação (SOBCV), do porcentual de enraizamento (ENRCS) e altura (ALTCS) das miniestacas na saída da casa de sombra; e de sobrevivência (SOB50), altura (ALT50), diâmetro de colo (DC50) e da massa de matéria seca da parte aérea (PSPA) e do sistema radicular (PSR) das plantas aos 50 dias de idade, em função das concentrações de PVP associado a $500 \mathrm{mg} \mathrm{L}^{-1}$ de AIB, dos quatro clones de Eucalyptus grandis x E. urophylla

Table 3 - Results of the Analysis of Variance (ANOVA) of survival data on mini-cuttings of four Eucalyptus grandis $x$ E. urophylla clones regarding greenhouse exit survival (SOBCV); shade house exit mini-cuttings rooting percentage (ENRCS) and height (ALTCS); survival (SOB50), height (ALT50), root collar diameter (DC50) and dry mass of the aerial portion (PSPA) and root system (PSR) of the plants at 50 days of age, as a result of concentrations of PVP associated with $500 \mathrm{mg} \mathrm{L}^{-1} \mathrm{IBA}$.

\begin{tabular}{|c|c|c|c|c|c|c|c|c|c|}
\hline \multirow{2}{*}{$\begin{array}{l}\text { Fontes de } \\
\text { variação }\end{array}$} & \multirow[t]{2}{*}{ GL } & \multicolumn{8}{|c|}{ Quadrados médios } \\
\hline & & $\begin{array}{c}\text { SOBCV } \\
(\%)\end{array}$ & $\begin{array}{c}\text { ENRCS } \\
(\%)\end{array}$ & $\begin{array}{l}\text { ALTCS } \\
(\mathrm{cm})\end{array}$ & $\begin{array}{c}\text { SOB50 } \\
(\%)\end{array}$ & $\begin{array}{l}\text { ALT50 } \\
(\mathrm{cm})\end{array}$ & $\begin{array}{l}\text { DC50 } \\
(\mathrm{mm})\end{array}$ & $\begin{array}{l}\text { PSPA } \\
\text { (g) }\end{array}$ & $\begin{array}{c}\text { PSR } \\
\text { (g) }\end{array}$ \\
\hline Clone (C) & 3 & $344,12^{*}$ & $11435,43^{*}$ & $4505,80^{*}$ & $14042,39^{*}$ & $5652,54^{*}$ & $17,03^{*}$ & $212,68^{*}$ & $21,18^{*}$ \\
\hline Trat. (T) & 6 & $108,93^{\mathrm{ns}}$ & $858,91^{*}$ & $48,92^{\mathrm{ns}}$ & $750,67^{*}$ & $62,83^{*}$ & $0,50^{\mathrm{ns}}$ & $4,33^{\mathrm{ns}}$ & $0,25^{\mathrm{ns}}$ \\
\hline $\mathrm{C}^{*} \mathrm{~T}$ & 18 & $243,48^{*}$ & $917,04^{*}$ & $69,17^{*}$ & $859,34^{*}$ & $84,43^{*}$ & $0,54^{*}$ & $7,10^{*}$ & $0,57^{\mathrm{ns}}$ \\
\hline Resíduo & 84 & 75,10 & 141,49 & 24,40 & 158,23 & 24,32 & 0,21 & 3,53 & 0,51 \\
\hline Média Geral & - & 95,5 & 75,1 & 32,6 & 71,0 & 35,6 & 2,9 & 6,8 & 1,9 \\
\hline $\mathrm{CV}_{\exp }(\%)$ & - & 11,1 & 22,9 & 28,1 & 26,7 & 28,5 & 29,5 & 26,3 & 23,9 \\
\hline
\end{tabular}

“ns” e “*” = não significativo e significativo, respectivamente, a 5\% de probabilidade, pelo teste F.

“ns" and “*” = not meaningful and significant, respectively, at 5\% probability by $F$ test.

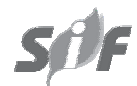

Revista Árvore, Viçosa-MG, v.34, n.6, p.961-972, 2010 

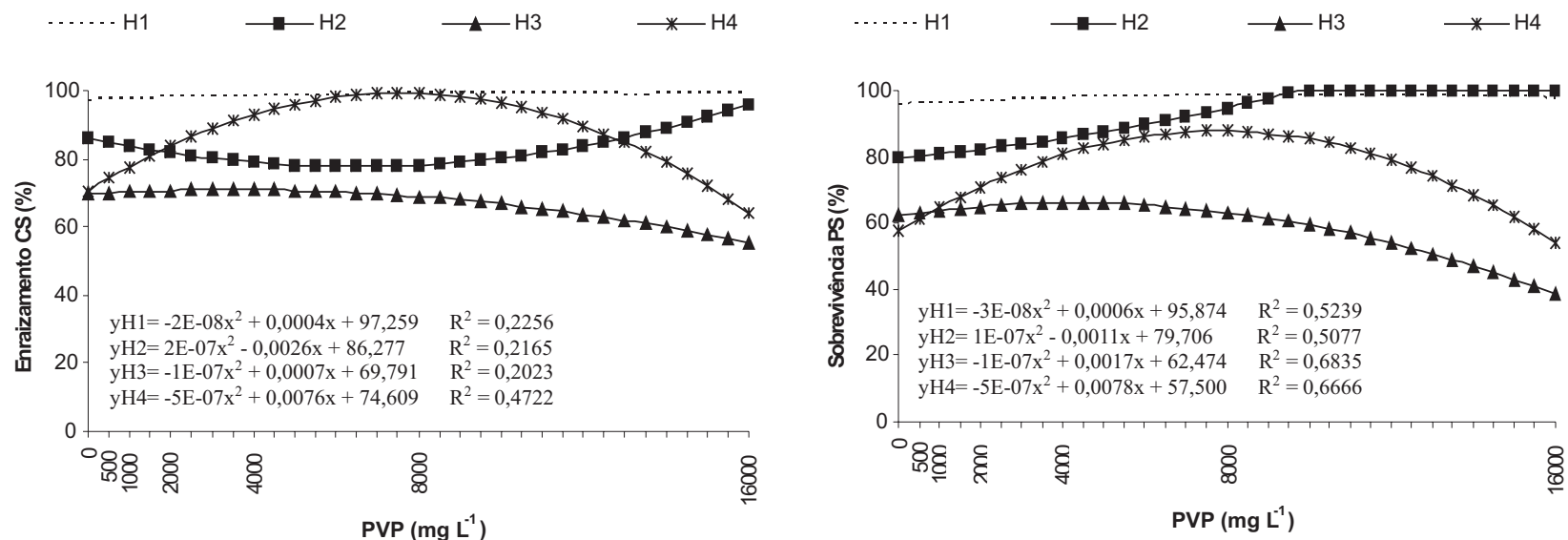

Figura 7 - Enraizamento e sobrevivência das miniestacas na saída da casa de sombra e a pleno sol, aos 35 e 50 dias de idade, respectivamente, em função da aplicação do antioxidante PVP associado a $500 \mathrm{mg}$ L-1 de AIB, dos quatro clones de Eucalyptus grandis x E. urophylla.

Figure 7 - Mini-cuttings of four Eucalyptus grandis $x$ E. urophylla clones shade house exit and in full sun rooting and survival, at 35 and 50 days of age, respectively, as a result of the application of PVP antioxidant associated with $500 \mathrm{mg} \mathrm{L-1} \mathrm{IBA.}$

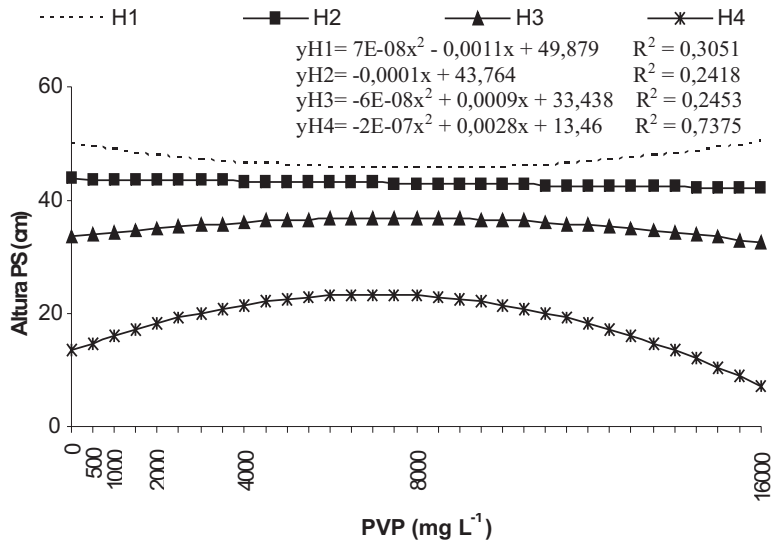

Figura 8 - Altura das miniestacas a pleno sol, aos 50 dias de idade, em função da aplicação do antioxidante PVP associado a $500 \mathrm{mg} \mathrm{L}^{-1}$ de AIB, dos quatro clones de Eucalyptus grandis x E. urophylla.

Figure 8-Mini-cuttings of four Eucalyptus grandis $x$ E. urophylla clones height in full sun, at 50 days of age, as a result of the application of $P V P$ antioxidant associated with $500 \mathrm{mg} \mathrm{L}^{-1}$ IBA.

exibiu os melhores resultados. Entretanto, nos clones H1, H2 e H3 os coeficientes de determinação $\left(R^{2}\right)$ nas análises de regressão apresentaram valores considerados baixos, denotando maior atenção na interpretação das equações de regressão, visando explicar as respostas de altura das miniestacas a pleno sol.
A hipótese era de que a aplicação, nas miniestacas, de PVP associado ao AIB promovesse aumento nos índices de enraizamento e sobrevivência, o que foi confirmado, principalmente, em um dos quatro clones estudados, demonstrando o efeito benéfico desse antioxidante.

Esses resultados confirmam, de certa forma, as respostas encontradas por Wendling et al. (2001), que observaram efeito positivo da aplicação do PVP nas maiores doses testadas (dosagens de PVP avaliadas: 0, 100, 500 1.000, 2.000 e $5.000 \mathrm{mg}^{-1} \mathrm{l}^{-1}$ )no enraizamento adventício deminiestacas de dois clones de Eucalyptus grandis.

\section{CONCLUSÕES}

As respostas dos clones em relação à aplicação dos antioxidantes ácido ascórbico, carvão ativado e PVP foram variadas e específicas, indicando efeito genotípico (clone) quanto ao porcentual de enraizamento e crescimento das miniestacas enraizadas em casa de vegetação, casa de sombra e a pleno sol dos quatro clones de Eucalyptus grandis x E. urophylla avaliados.

\section{AGRADECIMENTOS}

À empresa International Paper do Brasil, pela oportunidade de realização deste trabalho, pela disponibilização do material genético (clones), e pelo apoio financeiro, de pessoal e de infra-estrutura. 


\section{REFERÊNCIA}

ARAÚJO, J. M. A. Química de alimentos: teoria e prática. Viçosa, MG: Universidade Federal de Viçosa, 1985. 355p.

ASSIS, T.; FETT-NETO, A. G.; ALFENAS, A. C. Current techniques and prospects for the clonal propagation of hardwoods with emphasis on Eucalyptus. In: WALTERS C.; CARSON M. (Eds.). Plantation Forest Biotechnology for the $21^{\text {st }}$ Century, Kerala: Research Signpost, 2004. p.303-333.

BERARDI, G.; INFANTE, R.; NERI, D. Micropropagation of Pyrus calleryana Den. From seedlings. Scientia Horticulturae, v.53, , p.157-165, 1993.

CORDEIRO, M. C. C. et al. Germinação in vitro de paricá (Schizolobium amazonicum Huber).

Revista Biotecnologia Ciência e Desenvolvimento, n.27, p.58-62, 2002.

DEBERGH, P. C.; READ, P. E. Micropropagation. In: DEBERGH, P. C.; ZIMMERMAN, R. H. (Eds.). Micropropagation technology and application. Dordrecht: Kluwer Academic Publishes, 1991. p.486-510.

ERIG,A. C.; SCHUCH, M.W.; BRAGA, E. J. B. Enraizamento in vitro de pereira (Pyrus communis L.) cv. Carrick. Ciência Rural, v.34, n.1, p.275-277, 2004.

GESTO, M. D. V.; VÁZQUEZ, A.; VIEITEZ, E. Rooting substances in water extracts of Castanea sativa and Salix viminalis. Physiologia Plantarum, v.40, n.4, p.265-268, 1977.

HAISSIG, B. E. Influences of auxins synergists on adventitious root primordium initiation and development. New Zealand Journal of Forestry Science, v.4, p.311-323, 1974.

HARTMANN, H. T. et al. Plant propagation: principles and practices. 7.ed. New Jersey: Prentice-Hall, 2002. 880p.

HIGASHI, E. N.; SILVEIRA, R. L. A.; GONÇALVES, A. N. Propagação vegetativa de Eucalyptus: princípios básicos e a sua evolução no Brasil. Piracicaba: IPEF, 2000. 11p. (Circular Técnica, 192).
OFFMANN, A.; FACHINELLO, J. C.; SANTOS, A. M. Propagação de mirtilo (Vaccinium asheireade) através de estacas. Pesquisa Agropecuária Brasileira, v.30, n.2, p.231-236, 1995.

KEFELI, V. I.; KADYRON, C. Sh. Natural growth inhibitors, their chemical and physiological properties. Annual Review of Plant Physiology, v.57, p.185-196, 1971.

LEE, T. T.; STARRATT, A. N.; JEVNIKAR, J. J. Regulation of enzymic oxidation of indole-3acetic acid by phenols: structure-activity relationships. Phytochemistry, v.21, n.3, p.517-523, 1982.

MANTOVANI, N. C.; FRANCO, E. T. H.; VESTENA, S. Regeneração in vitro de LouroPardo (Cordia trichotoma (Vellozo) Arrabida ex Steudel). Ciência Florestal, v.11, n.2, p.93-101, 2001.

ONO, E. O.; RODRIGUES, J. D. Aspectos da fisiologia do enraizamento de estacas caulinares. Jaboticabal: Funep, 1996. 81p.

RANA, H. S.; CHADHA, T. R. Studies on the clonal propagation of Prunus species and their relationship with some biochemical characters. Progressive Horticulture, v.21, n.3-4, p.329335, 1989. CD-ROM

RIBAS, K. C. Interações entre auxina e cofatores do enraizamento na promoção do sistema radicular em estacas de Eucalyptus grandis W. Hill ex Maiden. 1997. 150f. Tese (Doutorado em Ciências Biológicas) - Universidade Estadual de São Paulo, Botucatu, 1997.

TAIZ, L.; ZEIGER, E. Fisiologia vegetal. Porto Alegre: Artmed, 2004. 719p.

TEIXEIRA, J.B. Limitações ao processo de cultivo in vitro de espécies lenhosas. Disponível em: <http://www.redbio.org.br $>$ Acesso em: 22 abr. 2004.

TITON, M.; XAVIER, A.; OTONI, W. C. Clonal propagation of Eucalyptus grandis using the mini-cutting and micro-cutting techniques. Scientia Forestalis, n.71, p.109-117, 2006.

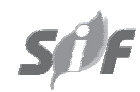

Revista Árvore, Viçosa-MG, v.34, n.6, p.961-972, 2010 
WENDLING, I.; XAVIER, A. Influência do ácido indolbutírico e da miniestaquia seriada no enraizamento e vigor de miniestacas de clones de Eucalyptus grandis. Revista Árvore, v.29, n.6, p.921-930, 2005.

WENDLING, I. et al. Propagação clonal de híbridos de Eucalyptus spp. por miniestaquia. Revista Árvore, v.24, n.2, p.181-186, 2000.

WENDLING, I. et al. Influência do antioxidante polivinilpirrolidona (PVP) no enraizamento de miniestacas de Eucalyptus grandis. In: SIMPÓSIO BRASILEIRO DE PÓS GRADUAÇÃO EM

ENGENHARIA FLORESTAL, 1., 2001, Santa Maria. Anais... Santa Maria, 2001. p.16-29. CD-ROM
WILSON, P. J.; van STADEN, J. Rhizocaline, rooting co-factors and the concept of promoters and inhibitors of adventitious rooting - a review. Annuals of Botany, v.66, n.4, p.479-490, 1990.

XAVIER,A.; WENDLING I.; SILVA, R.L.

Silvicultura clonal: princípios e técnicas. Viçosa, MG: Universidade Federal de Viçosa, 2009. 272p.

XAVIER, A.; WENDLING, I. Miniestaquia na clonagem de Eucalyptus. Viçosa, MG: SIF, 1998. 10p. (Informativo Técnico SIF, 11).

ZIV, M.; HALEVY, A. H. Control of oxidative browning and in vitro propagation of Strelitzia reginae. HortScience, v.18, p.434-436, 1983. 